\title{
Assessment of violence risk in 440 psychiatric patients in China: examining the feasibility and acceptability of a novel and scalable approach (FoVOx)
}

Shaoling Zhong ${ }^{1}$, Rongqin $\mathrm{Yu}^{2}$, Robert Cornish ${ }^{2}$, Xiaoping Wang ${ }^{1 *}$, Seena Fazel ${ }^{2^{*}}$ and FoVOx group

\begin{abstract}
Background: Violence risk assessment is a routine part of clinical services in mental health, and in particular secure psychiatric hospitals. The use of prediction models and risk tools can assist clinical decision-making on risk management, including decisions about further assessments, referral, hospitalization and treatment. In recent years, scalable evidence-based tools, such as Forensic Psychiatry and Violent Oxford (FoVOx), have been developed and validated for patients with mental illness. However, their acceptability and utility in clinical settings is not known. Therefore, we conducted a clinical impact study in multiple institutions that provided specialist mental health service.

Methods: We followed a two-step mixed-methods design. In phase one, we examined baseline risk factors on 330 psychiatric patients from seven forensic psychiatric institutes in China. In phase two, we conducted semi-structured interviews with 11 clinicians regarding violence risk assessment from ten mental health centres. We compared the FoVOx score on each admission $(n=110)$ to unstructured clinical risk assessment and used a thematic analysis to assess clinician views on the accuracy and utility of this tool.

Results: The median estimated probability of violent reoffending (FoVOx score) within 1 year was 7\% (range 1-40\%). There was fair agreement (72/99, 73\% agreement) on the risk categories between FoVOx and clinicians' assessment on risk categories, and moderate agreement (10/12, 83\% agreement) when examining low and high risk categories. In a majority of cases $(56 / 101,55 \%)$, clinicians thought the FoVOx score was an accurate representation of the violent risk of an individual patient. Clinicians suggested some additional clinical, social and criminal risk factors should be considered during any comprehensive assessment. In addition, FoVOx was considered to be helpful in assisting clinical decisionmaking and individual risk assessment. Ten out of 11 clinicians reported that FoVOx was easy to use, eight out of 11 was practical, and all clinicians would consider using it in the future.
\end{abstract}

Conclusions: Clinicians found that violence risk assessment could be improved by using a simple, scalable tool, and that FoVOx was feasible and practical to use.

Keywords: Violence risk assessment, Prediction, Severe mental illness, Recidivism, Forensic psychiatry, FoVOx

\footnotetext{
*Correspondence: xiaop6@csu.edu.cn; seena.fazel@psych.ox.ac.uk

'Department of Psychiatry, National Clinical Research Center for Mental

Disorders, The Second Xiangya Hospital, Central South University, Changsha,

China

${ }^{2}$ Department of Psychiatry, University of Oxford, Oxford, UK
}

(C) The Author(s). 2021, corrected publication 2021. Open Access This article is licensed under a Creative Commons Attribution 4.0 International License, which permits use, sharing, adaptation, distribution and reproduction in any medium or format, as long as you give appropriate credit to the original author(s) and the source, provide a link to the Creative Commons licence, and indicate if changes were made. The images or other third party material in this article are included in the article's Creative Commons licence, unless indicated otherwise in a credit line to the material. If material is not included in the article's Creative Commons licence and your intended use is not permitted by statutory regulation or exceeds the permitted use, you will need to obtain permission directly from the copyright holder. To view a copy of this licence, visit http://creativecommons.org/ licenses/by/4.0/. The Creative Commons Public Domain Dedication waiver (http://creativecommons.org/publicdomain/zero/1. 0/) applies to the data made available in this article, unless otherwise stated in a credit line to the data. 


\section{Background}

Many population-based and cohort studies have reported a small but clinically important increased risk of violence in many mental disorders [1,2], which is modifiable, and can lead to disruptions in care, increased stigmatization, and substantial healthcare costs associated with detention in secure hospitals [3, 4]. Violence risk assessment is considered one part of a multi-faceted approach to reduction of violence risks and can assist clinical decision-making about psychiatric admission, management, and discharge, and improving linkage to violence-reducing interventions such as optimization of medication, more frequent follow-up and additional psychosocial treatments [5]. Currently, however, many mental health professionals, including those in China, tend to rely predominantly on unstructured clinical judgment [6], partly due to lack of validated tools. A recent meta-analysis has suggested that existing violence risk assessment tools such as Historical, Clinical, Risk Management-20 (HCR-20) and Psychopathy Checklist Revised (PCL-R) have poor to moderate predictive validity in Chinese settings [7], which corresponds with poor validity in field studies in people leaving hospital and prison in other countries $[8,9]$. Another limitation of current instruments has been that they are often resource-intensive and time-assuming. For example, an initial assessment using HCR-20 usually takes 15 person-hours [10], professional time that could be better directed towards treatments. Furthermore, current violence assessment tools have been developed on heterogeneous and non-psychiatric populations and were not developed using high quality methods [11]. A particular high-risk group are patients who have criminal histories, and on discharge from forensic (or secure) hospitals, reoffending risk is estimated at 4484 per 100,000 person-years according to a recent review [12]. Individual studies have found $6 \%$ reoffend within 6 months of discharge in Germany [13], and 49\% repeat offend within around 3 years in England [14].

To address shortcomings with previous instruments, a new prediction rule (Forensic Psychiatry and Violence tool Oxford, FoVOx [15]) has recently been developed to estimate violent risk of patients following discharge from secure psychiatric hospitals. The FoVOx tool was developed using a longitudinal cohort study of 2248 patients in Sweden. This tool is quick and simple to use, and consists 12 routinely collected risk factors, including demographic (i.e. sex, age, and employment at admission), criminal (i.e. previous violent crime, previous serious violent crime) and clinical factors (i.e. primary discharge diagnosis, drug use disorder at point of hospitalization or discharge, any lifetime drug use disorder, alcohol use disorder at point of hospitalization or discharge, personality disorder at discharge). The development FoVOx study was conducted using high quality methods including a pre-specified protocol, transparent reporting of results, and translation into a freely-available online calculator (https://oxrisk.com/fovox/). The tool was internally validated and has a good predictive accuracy (area under the curve $=0.77$ at 12 and 24 months). It remains to be externally validated, which will likely need a multicountry study due to the relatively small numbers of patients in forensic hospitals in any particular country. A recent study has showed that the tool can be adapted for use in prison hospitals in Germany with good performance in predicting inpatient violence [16]. Furthermore, there are very few studies of risk assessment tools in low and middle income countries and the feasibility of such approaches needs to be examined in such settings.

To further examine the utility of the FoVOx tool, we conducted a clinical impact study to assess: (i) the distribution of violence risk scores in a representative Chinese cohort of forensic psychiatric patients and (ii) the potential impact of the tool on mental health professionals in assisting their decision-making using qualitative methods. This study, thus, primarily aims to test acceptability and potential utility of using one standardised risk assessment tool in Chinese psychiatric settings.

\section{Methods}

Study design and participants

We used a mixed-methods approach to examine the feasibility of FoVOx (Supplemental materials, Figure 1). This study includes two phases. In phase 1, we retrospectively examined patients who had committed violent crimes and admitted for forensic psychiatric assessments between 1 January 2011 and 31 December 2011 in seven forensic psychiatric institutes in Hunan Province, China. We manually reviewed all medical files of patients under forensic psychiatric assessments in Hunan to extract data on variables included in the FoVOx risk assessment tool. We included patients who were (i) $\geq 18$ years old; (ii) diagnosed with mental illness following the criteria of the International Classification of Diseases 10th Revision; (iii) Hunan residents; and (iv) suspected of a violent offence. We excluded patients who were diagnosed after crime dates.

In phase 2, we used a convenience sampling method to recruit clinicians from ten mental health centres and conducted in-depth interviews using a semi-structured interview questionnaire between 1 May 2019 and 31 December 2019. We included clinicians who had experience with violent risk assessment. Based on a purposive sampling procedure and principle of data saturation, we interviewed 11 clinicians for their opinion on the impact of the tool. Unlike external validations, currently there is no consensus on the minimum number of participants required for qualitative feasibility studies [17]. However, it has been suggested that a sample size of ten is sufficient to identify potential issues of a tool [18]. 


\section{Risk factors}

Two groups of risk factors were considered based on whether they were presented in the original model in FoVOx (see: https://oxrisk.com/fovox/). Group 1 risk factors includes four broad classes of variables: socialdemographic factors (sex, age, employment before admission), criminological factors (any previous violent crime, any previous serious violent crime), clinical factors (inpatient episodes, length of stay), and psychiatric diagnosis (primary discharge diagnosis, drug use disorder at hospitalization or discharge, lifetime drug use disorder, alcohol use disorder at hospitalization or discharge, personality disorder diagnosis at discharge).

In this study, we defined 'full-time students' as 'employed' and 'farmers' as 'unemployed' to reflect the local context (as farmers are typically in insecure and irregular employment). We did not include one variable (length of stay in forensic hospital) as it is not applicable in this study setting (i.e. the patients were to be transferred to forensic hospitals at the time of assessment).

Group 2 were proxy variables which were approximate to the original variables in FoVOx and were associated with outcomes. For example, any previous diagnosis of drug use disorder was indicated with a comparable variable, history of drug use; any previous diagnosis of alcohol use disorder was indicated with history of alcohol use. History of alcohol use and drug use was adopted as proxy factors for lifetime alcohol use disorder and lifetime drug use disorder, respectively.

\section{Semi-structured interview survey}

We developed a standardized tool to collect data from clinicians. The interview questionnaire was reported in a previous study [19] and was translated. We explored the following domains to examine the feasibility of FoVOx in clinical settings, including:

- Accuracy (i.e. Do you think that the FoVOx score was an accurate representation of the risk that this patient posed at the time of assessment?);

- Impact (i.e. Do you think that knowing the patient's FoVOx score at the point of assessment would have been of any clinical benefit, e.g. would it have altered your management of this patient?);

- Practicability (i.e. Having seen the tool, do you think that the FoVOx web-based calculator would be practical to use as part of a discharge assessment/ plan?);

- Simplicity (i.e. Do you think that it would be possible to complete the FoVOx tool without having to refer to the clinical notes in the majority of cases?);

- Future use (i.e. Will you use FoVOx in the future?).

\section{Procedures}

In phase 1 , as part of the forensic psychiatric assessments, the current episode and clinical diagnosis were assessed by a minimum of two forensic psychiatrists. Information (demographic data, medical records and criminal files) were collected from medical records. These were also used to collect the history of medical factors (inpatient episodes, length of stay). All data were retrieved by an independent researcher (CL) using a standard form. Then, the data were evaluated by a second researcher (SZ) for eligibility.

In phase 2, before the interview, clinicians were asked to complete FoVOx for up to 10 patients that they had assessed. During the interview, clinicians were asked to estimate the violence risk level (low/medium/high) of their patient before they saw the FoVOx score. Then, they were given the FoVOx risk score of the same patient (which is a probability score ranging from 0 to $20 \%$ ). Afterwards, clinicians were asked whether they considered the FoVOx score was accurate for this particular patient and whether there was any clinical benefit of knowing the FoVOx risk category and probability score at the point of assessment. Finally, clinicians were asked whether the tool was practicable and simple to use and whether they would use FoVOx in the future.

\section{Outcomes}

The primary outcomes were predictor information on the patient cohort, FoVOx scores of the patients, and clinicians' responses to the qualitative questionnaire.

\section{Analytic strategies}

In the quantitative analyses, we calculated the frequency of risk factors for categorical data and mean (standard deviation) for continuous data. To explore the feasibility of collecting the required data, we recorded the proportion of missing data and coded them as 'unknown'. We calculated agreement in risk assessment categories (i.e. low/medium/high) between the judgement from the clinicians and the FoVOx score. We combined medium and high-risk categories and compared it to the low risk category, and calculated Cohen's kappa [20]. As an alternative approach, we also calculated kappa to compare low with high-risk categories.

In qualitative analyses, we recorded semi-structured interviews with clinicians. We made notes during the interview and used their original words as many as possible, and also reported back the interpretation of their views to give them an opportunity to confirm or amend this. SZ analysed the records, coded items and then grouped items into separate themes. A second researcher (RC) repeated the coding independently and the two researchers reached a consensus on the data interpretation. 


\section{Results}

\section{Sample}

In the first phase, 330 patients were included $(17.6 \%$ females), with a median age of 36 years (ranging from 25 to 47). In phase 2, we identified 110 admissions for psychiatric assessments in forensic psychiatric hospitals. Nine patients were excluded, as five of them did not have mental illness at the time of the index crime, three had unclear information on risk factors, and one had not committed any crime. In total, data from 101 patients were analysed. The number of assessed patients per clinician ranged from 6 to 10. Among 11 clinicians interviewed, 9 reported that they did not use any risk assessment tool but adopted a standard review of clinical and criminal reports and clinical interviews. Only one clinician reported using a risk assessment tool that was developed locally by the hospital and one clinician reported using HCR-20 items.

\section{Baseline characteristics and risk factors}

The distribution of the risk factors in this cohort and comparisons with the development one are shown in Table 1. Most patients were male (82.4\%), unemployed (87.3\%), had a history of violent crime (62.4\%), and had a diagnosis of schizophrenia-spectrum disorders (67.9\%).

\section{FoVOx scores}

We calculated FoVOx scores based on data from the clinical recodes for each patient included at the phase 2 and also asked clinicians for their risk rating (Table 2). Based on FoVOx, the median probability of violent reoffending within 2 years was $7 \%$ (range from 1 to $40 \%)$. As for risk categories, $17(16.8 \%)$ of individuals were categorized as low risk, $76(75.2 \%)$ medium risk and 6 (5.9\%) high risk based on pre-specified thresholds.

\section{Concordance between FoVOx and clinical judgement}

We calculated concordance between the risk levels (i.e. low/medium/high) obtained from the FoVOx in relation to clinical judgement in individual patients. For 2 individuals, clinicians reported unable to provide the risk category, and the comparison was not made. We found agreement between risk categories based on FoVOx and those from clinicians in $72 \%$ of cases (72 out of $99,73 \%$ agreement, kappa $=0.21$ indicating fair agreement). For cases with disagreement between risk categories, clinicians tended to score patients at a lower risk (18 out of 27 the cases) than the FoVOx category (9 out of 17). When using two risk bins (low and high), 83\% (10 out of 12) cases were agreed between FoVOx and clinicians $(83 \%$ agreement, $\mathrm{kappa}=0.57$, indicating moderate agreement).

For the majority of cases $(56 / 101,55.4 \%)$, clinicians thought that the FoVOx score was an accurate
Table 1 Distribution of risk factors for violence in severe mental illness in Hunan and in comparison with the original Swedish cohort

\begin{tabular}{|c|c|c|c|c|}
\hline \multirow{3}{*}{$\begin{array}{l}\text { Variables } \\
\text { Age (IQR) }\end{array}$} & \multicolumn{2}{|c|}{$\begin{array}{l}\text { Hunan }(N= \\
330)\end{array}$} & \multicolumn{2}{|c|}{$\begin{array}{l}\text { Sweden }(n= \\
2248)\end{array}$} \\
\hline & 36 & $25-47$ & 36 & $29-45$ \\
\hline & $\mathrm{n}$ & $\%$ & $\mathrm{n}$ & $\%$ \\
\hline \multicolumn{5}{|l|}{ Gender } \\
\hline Male & 272 & 82.4 & 1938 & 86.0 \\
\hline Female & 58 & 17.6 & 310 & 14.0 \\
\hline \multicolumn{5}{|l|}{ Employment } \\
\hline Employed & 27 & 8.2 & 171 & 7.6 \\
\hline Unemployed & 288 & 87.3 & 2077 & 92.4 \\
\hline \multicolumn{5}{|l|}{ Any previous alcohol use disorder } \\
\hline Yes & - & - & 780 & 34.7 \\
\hline \multicolumn{5}{|l|}{ Any previous drug use disorder } \\
\hline Yes & - & - & 1050 & 49.0 \\
\hline \multicolumn{5}{|l|}{ Previous violent crime } \\
\hline Yes & 206 & 62.4 & 1836 & 81.7 \\
\hline \multicolumn{5}{|l|}{ Previous inpatient episodes } \\
\hline$\geq 5$ & 8 & 2.4 & 1110 & 52.6 \\
\hline $3-4$ & 25 & 7.6 & - & - \\
\hline $1-2$ & 90 & 27.3 & - & - \\
\hline 0 & 10 & 3.0 & - & - \\
\hline \multicolumn{5}{|l|}{ Primary diagnosis } \\
\hline Schizophrenia-spectrum disorders & 224 & 67.9 & 944 & 45.7 \\
\hline Bipolar disorder & 29 & 8.8 & 130 & 6.3 \\
\hline Unipolar depression & 0 & 0 & 97 & 4.7 \\
\hline Anxiety disorders & 2 & 0.6 & 139 & 6.7 \\
\hline Other & 75 & 22.7 & 754 & 36.5 \\
\hline \multicolumn{5}{|l|}{$\begin{array}{l}\text { Drug use disorder at hospitalization } \\
\text { or discharge }\end{array}$} \\
\hline Yes & 16 & 4.8 & 540 & 26.2 \\
\hline \multicolumn{5}{|l|}{$\begin{array}{l}\text { Alcohol use disorder at hospitalization } \\
\text { or discharge }\end{array}$} \\
\hline Yes & 9 & 2.7 & 217 & 10.6 \\
\hline \multicolumn{5}{|l|}{ Personality disorder at discharge } \\
\hline Yes & 4 & 1.2 & 536 & 27.3 \\
\hline
\end{tabular}

Table 2 Risk categories assigned by clinicians compared with categories based on FoVOx scores

\begin{tabular}{lll}
\hline & FoVOx & Medium/High \\
\cline { 3 - 3 } & Low & \\
\hline Clinicians & & 18 \\
Low & 8 & 64 \\
Medium/High & 9 & \\
\hline
\end{tabular}

FoVOx risk categories are based on pre-specified risk levels. Low: $<5 \%$; medium: 5-20\%; high:> 20\% 
representation of the violence risk. In $14.9 \%$ of cases (15/101), clinicians were unable to comment about FoVOx accuracy. In 30/101 (29.7\%) of cases, clinicians thought that FoVOx was not wholly accurate and were asked to give reasons. They identified the main reason as being that certain individual risk factors were not included in FoVOx and summarised these into three groups (Table 3). First, clinicians stated that certain clinical risk factors were not identified, such as a family history of mental illness, psychotic symptoms, adherence with medication, and response to treatment. These factors were thought to contribute to risk in both directions: if the patient has a poor adherence or partial response to medication, the FoVOx score might be an underestimate and vice versa. "The characteristic of the disease is not identified in the tool. In this case, the patient has a poor response to treatment". "The FoVOx score is high in this case. However, the patient has good medication compliance". A second group of possible missing factors were social ones, including family supervision, social support and social status. "The score rated by the tool was low. But this patient may still be quite aggressive, as he has a strong family history of mental illness and poor social support." Finally, clinicians reported that more criminal risk factors should be considered, including the individual's attitude towards the violent crime committed, recent violent behaviour in hospital, and instrumental reasons for the violence. "The patient had this violence incident for a certain realistic reason. The victim owed money and did not pay it back".

\section{Viewpoints on utility at the point of admission}

We asked clinicians if it is beneficial to know FoVOx scores at the point of first assessment. Clinicians reported that it would be helpful in 52 (50\%) out of 101 cases. A summary of the qualitative feedback is presented in Table 4. We identified two themes. First, clinicians viewed that the FoVOx tool can assist clinical decision-making. Clinicians frequently mentioned that it can be used as part of patient management, especially for cases with a high risk. "In a high-risk case like this, I would suggest compulsory medical treatment in the final report, and would refer to the tool, including the probability value from the tool". It was reported that using the FoVOx score can facilitate liaison with third parties without a professional background. "The scores are intuitive and easy for people without a professional background to understand. They could be used as a basis for communicating with patients". It may also improve information sharing among medical staff. It was reported that for individuals with a low or medium risk, no difference would be made in management decisions as majority of them would be sent to prisons rather than forensic hospitals. For these cases, "the aim at the time of assessment is mainly to estimate the current violent risk rather than future risk."

The second theme was how the FoVOx tool could impact on individual risk assessment. Some clinicians reported that FoVOx could be used as part of clinical management and may support clinical judgement. Others said that the FoVOx tool would not contribute if it differed from clinical judgement. Some clinicians noted that it can serve as a reminder to consider additional risk factors: when FoVOx has a higher value than the clinicians' judgement, they would consider if there are additional risk factors; and when FoVOx has a lower value than clinicians' judgement, they would consider if there are other protective factors. A very few found that

Table 3 Viewpoints on what other individual and social factors are relevant for violence risk assessment (case by case)

\begin{tabular}{|c|c|c|c|}
\hline Theme & Sub-theme & $\begin{array}{l}\text { FoVOx score higher than clinical judgement as } \\
\text { the tool does not include the following protective factors }\end{array}$ & $\begin{array}{l}\text { FoVOx score lower than clinical judgement } \\
\text { as the tool does not include the following risk factors }\end{array}$ \\
\hline \multirow{3}{*}{$\begin{array}{l}\text { Social risk } \\
\text { factors }\end{array}$} & supervision & good family support & poor family support (no close family, anger towards family) \\
\hline & social support & good social support & poor social support \\
\hline & social status & had an official job & homeless; low social status \\
\hline \multirow{4}{*}{$\begin{array}{l}\text { Clinical risk } \\
\text { factors }\end{array}$} & family history & - & history of mental illness in family members \\
\hline & disease related & - & $\begin{array}{l}\text { active and positive symptoms; poor insight; chronic disease; early } \\
\text { onset age }\end{array}$ \\
\hline & treatment related & good response to medication; good compliance & $\begin{array}{l}\text { poor response to medication; poor compliance; } \\
\text { not receiving systematic treatment }\end{array}$ \\
\hline & diagnosis related & $\begin{array}{l}\text { only had history of psychiatric diagnosis, no } \\
\text { recurrence afterwards }\end{array}$ & high impulsivity; low self-control \\
\hline \multirow[t]{3}{*}{$\begin{array}{l}\text { Criminal risk } \\
\text { factors }\end{array}$} & $\begin{array}{l}\text { response to the violent } \\
\text { crime committed }\end{array}$ & - & not feeling guilty or regretful \\
\hline & $\begin{array}{l}\text { previous violent } \\
\text { history }\end{array}$ & - & $\begin{array}{l}\text { history of repeated violence; frequent recent violent } \\
\text { behavior in hospital }\end{array}$ \\
\hline & individual factors & $\begin{array}{l}\text { triggers/underlying reasons for crime may have } \\
\text { been resolved }\end{array}$ & $\begin{array}{l}\text { short length of imprisonment } \\
\text { triggers/underlying reasons for crime had not been } \\
\text { resolved }\end{array}$ \\
\hline
\end{tabular}


Table 4 Viewpoints on utility at the point of admission (case by case)

\begin{tabular}{|c|c|c|c|}
\hline Themes & Sub-theme & Helpful & Not helpful \\
\hline \multirow[t]{3}{*}{$\begin{array}{l}\text { Assist } \\
\text { decision } \\
\text { making }\end{array}$} & $\begin{array}{l}\text { As part of disposal } \\
\text { suggestions }\end{array}$ & $\begin{array}{l}\text { For high-risk individuals, clinicians will refer to the tool } \\
\text { and make suggestions on compulsory } \\
\text { treatment to guide disposal for the law } \\
\text { enforcement agencies. }\end{array}$ & $\begin{array}{l}\text { No difference in disposal decision for low- } \\
\text { or moderate-risk individuals: patients will } \\
\text { go to prisons. }\end{array}$ \\
\hline & In liaison with third parties & $\begin{array}{l}\text { Help to explain to people without a } \\
\text { professional background using a more } \\
\text { objective tool, e.g. patients, family members, } \\
\text { the police }\end{array}$ & $\begin{array}{l}\text { Other agencies care about categorical risk } \\
\text { levels (e.g. high/low) rather than } \\
\text { probability scores. }\end{array}$ \\
\hline & $\begin{array}{l}\text { In liaison with other } \\
\text { clinicians }\end{array}$ & $\begin{array}{l}\text { Consistent risk levels; able to communicate } \\
\text { among clinicians and nurses. }\end{array}$ & \\
\hline \multirow[t]{4}{*}{$\begin{array}{l}\text { Impact on risk } \\
\text { assessment }\end{array}$} & $\begin{array}{l}\text { As part of clinical plan and } \\
\text { management }\end{array}$ & $\begin{array}{l}\text { Add supportive information, and possible } \\
\text { to choose a more conservative risk assessment plan }\end{array}$ & $\begin{array}{l}\text { If there is a difference between: FoVOx scores and } \\
\text { clinical judgement, clinicians might revert to clinical judgement. }\end{array}$ \\
\hline & Reassurance & $\begin{array}{l}\text { Confirm and support clinical assessment if } \\
\text { the risk levels between clinicians and FoVOx are consistent }\end{array}$ & \\
\hline & $\begin{array}{l}\text { Existing perceptions of risk } \\
\text { assessment }\end{array}$ & The FoVOx score provides an objective view & $\begin{array}{l}\text { The tool has not been externally } \\
\text { validated yet; } \\
\text { Not sure how to use probability value. Not clear from online } \\
\text { calculator how risk factors are weighted. }\end{array}$ \\
\hline & $\begin{array}{l}\text { Reminders for added risk } \\
\text { factors }\end{array}$ & $\begin{array}{l}\text { Clinicians would consider other risk factors if FoVOx has a } \\
\text { higher value and would consider protective factors if } \\
\text { FoVOx has a lower value than clinician } \\
\text { judgement }\end{array}$ & $\begin{array}{l}\text { Not many clinical } \\
\text { and dynamic factors }\end{array}$ \\
\hline
\end{tabular}

the tool may not be as helpful as insufficient risk factors were included in the tool.

\section{Overall views of practicality and future use}

After showing the clinicians the FoVOx tool, 10 out of 11 (91\%) clinicians reported that it would be possible to complete the FoVOx score calculation without having to refer to the clinical notes in majority of cases. One clinician noted that it would be safer to refer to additional information. Three reported that the FoVOx tool had practical difficulties. We identified two themes noted by these clinicians: some risk factors were not included in the tool and some risk factors needed further adjustment (see Table 5 for a summary).
All 11 clinicians reported that they would use FoVOx in the future. We identified two main themes (Table 5): there is a need for tools in China and the advantages of FoVOx. "At present, there is no such tool in China, and the variables included in the (FoVOx) tool are really important. If the tool is further verified, it can be used as a supplement (in risk assessment/management plan). But to be more cautious, other factors should be considered as well".

\section{Discussion}

We completed the FoVOx risk assessment tool on 330 patients who had committed a crime and had undertaken a full psychiatric assessment in one province in China. We then, based on a sample of another 110

Table 5 Viewpoints on practicality and future use of FoVOx risk assessment tool

\begin{tabular}{|c|c|c|}
\hline Themes & Sub-theme & Reasons \\
\hline \multirow[t]{4}{*}{$\begin{array}{l}\text { Will use in the } \\
\text { future }\end{array}$} & FoVOx specific & $\begin{array}{l}\text { simple items, easy to measure; quick, convenient and free calculator; important risk } \\
\text { factors included; reliable, consistent with clinical judgment; well developed and } \\
\text { will use it if further validated; rather objective }\end{array}$ \\
\hline & Need for tools & need for a standardized tool; there is no tool currently \\
\hline & Information sharing & provides informative data to support; help to explain to judges \\
\hline & $\begin{array}{l}\text { Impact on risk } \\
\text { management }\end{array}$ & reassurance with clinical judgements; easy to refer using low/middle/high categories \\
\hline \multirow[t]{4}{*}{ Limited use } & Risk factors not identified & only a few items were included; the risk factors are not associated with high variance \\
\hline & & $\begin{array}{l}\text { numbers of violence incidence, incentives for violence, family support, } \\
\text { education level, current symptoms, medication adherence, duration of disease }\end{array}$ \\
\hline & $\begin{array}{l}\text { Risk factors need } \\
\text { adjustment }\end{array}$ & $\begin{array}{l}\text { Few diagnoses of personality disorders are made in China. It is difficult for judges to } \\
\text { understand. } \\
\text { There is no special treatment for PD, and may increase the stigma towards } \\
\text { the individual with PD. }\end{array}$ \\
\hline & & Data on diagnosis of drug abuse is not commonly collected in China. \\
\hline
\end{tabular}


patients from different provinces, assessed the perceived accuracy, usefulness and feasibility of the FoVOx tool by conducting in-depth interviews with clinicians.

We found that most items contained within the FoVOx tool could be identified quickly and by clinician recall. Some items needed modification, and there are differences between forensic psychiatric populations in Sweden and China. Although age, gender and employment at the point of admission were similarly distributed, patients in China were less likely to have committed a previous violent crime ( $62.4 \%$ vs $81.7 \%)$, and much less likely to have had multiple admissions to psychiatric hospital (2.4\% having had five or more admissions vs 52.6\%). Patients in China were more likely to have a primary diagnosis of schizophrenia, and personality disorder was less common. Substance use disorders, both for alcohol and drugs, were less prevalent in the Chinese sample. These differences in prevalence do not lead to more inaccurate risk scores assuming the effect of each risk factor remains similar.

Despite these differences in the prevalence of risk factors, the FoVOx tool was considered acceptable by clinicians, with interviews suggesting strengths including its ability to assist with clinical decision-making and increase transparency among risk assessments conducted by different clinicians. In addition, the online risk score output includes easily understandable information which could facilitate communication with other agencies. Furthermore, the tool may help to identify risk factors not identified in unstructured clinical assessment.

Qualitative analysis found that, in some cases, clinicians felt that FoVOx scoring was limited as it did not account for certain individual factors. Some of these factors may however be measured indirectly by FoVOx. For example, close supervision was considered by clinicians to be missing for some cases as a factor reducing risk [21]. We did not include the item on length of stay for patients as they were being scored at the time of transfer to hospital rather than discharge, but this may be overlap with length of stay variable. Normally, patients with a length of stay of over 1 year are likely to have increased levels of monitoring after discharge. Also, some of these perceived omissions do not actually have an impact on the risk of recidivism. However, some of them do, such as high levels of acute psychopathology and poor adherence to treatment [22]. These factors are harder to measure in a straightforward binary way, and are liable to unreliable measurement. Such factors will also change dynamically over time and depend on the other matters, such as level of insight and the level of treatment compulsion based on their legal status. One solution may be to combine FoVOx scoring with other dynamic risk assessment tools [23] that provide serial monitoring of risk.
Another main finding is the absence of currently used violence risk assessment tools in China. Of 11 participants, only two currently used a formal risk assessment tool. There are significant variations in risk assessment practice worldwide, with professionals in Asia using risk instruments less frequently than in Europe and North America [24]. Thus there is a need for a freely available, transparent, scalable, and well-designed risk assessment tools for use in China and other countries at similar points in the development of their mental health services, such as other middle-income countries in East Asia.

Another implication is that the agreement level between the judgement from the clinicians and the calculation from FoVOx was different when three risk categories (i.e. low/medium/high) and two risk categories (low and high) were used. A different approach would be to allow clinicians and researchers to maximize either sensitivity or specificity depending on the different expected prevalences of the outcome, although this would require careful collection of historical data.

\section{Limitations}

Although seeking to understand the acceptability and utility of predictive tools is important, this is one part of a wider picture that needs to be considered as part of any implementation strategy. Another is external validation where a cohort is followed up over 1-2 years and information on outcomes collected. This would complement the present feasibility study, which focuses on useability and clinical utility. This should be pursued, although there are significant challenges in doing this in a forensic psychiatric population, given the large number of cases required. A large multicentre trial would be required in order to do this, and the feasibility of this will need to be determined.

Some items within the FoVOx tool may need to be adapted to suit the local characteristics. For example, personality disorder was felt to be present in a very small number of cases in this sample. Such diagnoses are likely to be more prevalent than we reported as we relied on medical records, albeit probably at a lower frequency than in Western European and North American samples [25]. Qualitative feedback suggested that there may be a reluctance to make personality disorder diagnoses due to fear of stigmatisation. Hence, this item could be altered as to whether the patient has significant personality traits, rather than basing it on a formal diagnosis. Similar changes could be made to items assessing substance misuse, as formal diagnoses relating to substance use are less likely, and in this study, we used proxy measures for these variables. 


\section{Conclusions}

Although developed in Sweden, we found that FoVOx was feasible and practicable to be used in a different country, China, with evidence that it could potentially impact patient management. Given that the tool relies on replicated risk factors, supported by a clear evidence base, most of which are categorised in a simple dichotomous way, FoVOx can be used in a minimally resource-intensive manner. Furthermore, the tool's scalability, transparency and easily understandable outputs underscore its potential to inform clinical care in high risk patient groups.

\section{Supplementary Information}

The online version contains supplementary material available at https://doi. org/10.1186/s12888-021-03115-3.

Additional file 1: Figure S1. Flow-diagram of the study design.

\section{Acknowledgments}

We thank Dr. Chun Li (Academy of Forensic Science) for assisting in data collection and Dr. Runsen Chen (University of Oxford) for help in data coding and interpretation. We appreciate the input from the FoVOx group members: Chen Chen (Academy of Forensic Science, China); Chun Li (Academy of Forensic Science, China); Dengke Zhang (Shaoxing University, China); Jun Wang (Wuxi Mental Health Center, China); Shenci Li (Hangzhou Ankang Hospital, China); Simei Zhang (Shenzhen Kangning Hospital, China), Xiaomin Zhu (Suzhou Guangji Hospital, the Affiliated Guangji Hospital of Soochow University, China); Ying Lv (Nanjing Brain Hospital, the affiliated Brain Hospital of Nanjing Medical University, China); Zhimei Wu (Hunan Brain Hospital, China)

FoVOx group.

Chen Chen ${ }^{3}$; Chun Li ${ }^{3}$; Dengke Zhang ${ }^{4}$; Jun Wang ${ }^{5}$; Shenci Li $i^{6}$; Simei Zhang ${ }^{7}$; Xiaomin Zhu' ${ }^{8}$; Ying $\mathrm{Lv}^{9}$; Zhimei $\mathrm{Wu}^{10}$.

${ }^{3}$ Academy of Forensic Science, Shanghai, China.

${ }^{4}$ Shaoxing University, Shaoxing, China.

${ }^{5}$ Wuxi Mental Health Center, Wuxi, China.

${ }^{6}$ Hangzhou Ankang Hospital, Hangzhou China.

${ }^{7}$ Shenzhen Kangning Hospital, Shenzhen, China.

${ }^{8}$ Suzhou Guangji Hospital, the Affiliated Guangji Hospital of Soochow University, Suzhou, China.

${ }^{9}$ Nanjing Brain Hospital, the affiliated Brain Hospital of Nanjing Medical University, Nanjing, China.

${ }^{10}$ Hunan Brain Hospital, Changsha, China.

\section{Authors' contributions}

SZ and SF conceived and designed the study, with input from RY and XW. SZ had full access to all data and conducted the analyses. SZ and RC drafted the manuscript. All authors interpreted the resulted and substantially revised the paper. All authors read and approved the final manuscript.

\section{Funding}

This research was funded in whole, or in part, by the Wellcome Trust (Grant no. 202836/Z/16/Z). For the purpose of Open Access, the author has applied a CC BY public copyright licence to any Author Accepted Manuscript version arising from this submission. SZ is funded by Hunan provincial Innovation Foundation for Postgraduate (Grant no. 2020zzts278)

\section{Availability of data and materials}

The datasets used and/or analysed during the current study are available from the corresponding author on reasonable request.

\section{Ethics approval and consent to participate}

The research was performed in accordance with the Declaration of Helsinki. The study protocol was approved by the institutional review board (IRB) of the National Clinical Research Center, the Second Xiangya Hospital, Central South University, China. All clinicians voluntarily joined the study and gave verbal informed consent. The need for written informed consent was waived by the IRB. The patient data was anonymized during the interviews, analyses and interpretations.

\section{Consent for publication}

Not applicable.

\section{Competing interests}

The authors declare that they have no competing interests.

Received: 19 November 2020 Accepted: 4 February 2021

Published online: 02 March 2021

\section{References}

1. Fazel S, Smith EN, Chang Z, Geddes JR. Risk factors for interpersonal violence: an umbrella review of meta-analyses. Br J Psychiatry. 2018;213: 609-14

2. Moberg T, Stenbacka M, Tengström A, Jönsson EG, Nordström P, Jokinen J. Psychiatric and neurological disorders in late adolescence and risk of convictions for violent crime in men. BMC Psychiatry. 2015;15:299.

3. Sariaslan A, Larsson H, Fazel S. Genetic and environmental determinants of violence risk in psychotic disorders: a multivariate quantitative genetic study of 1.8 million Swedish twins and siblings. Mol Psychiatry. 2016;21:1251-6.

4. Senior M, Fazel S, Tsiachristas A. The economic impact of violence perpetration in severe mental illness: a retrospective, prevalence-based analysis in England and Wales. Lancet Public Health. 2020;5:e99-106.

5. Fazel S, Zetterqvist J, Larsson H, Långström N, Lichtenstein P. Antipsychotics, mood stabilisers, and risk of violent crime. Lancet. 2014;384:1206-14.

6. Ho RMY, Lau JSF, Cheung HHK, Lai TTS, Tam VFL, Chan WL, et al. Evaluation of a model of violence risk assessment (HCR-20) among adult patients discharged from a gazetted psychiatric hospital in Hong Kong. J Forensic Psychiatry Psychol. 2013:24:479-95.

7. Zhou J, Witt K, Xiang Y, Zhu X, Wang X, Fazel S. Violence risk assessment in psychiatric patients in China: a systematic review. Aust N Z J Psychiatry. 2016;50:33-45

8. Jeandarme I, Pouls C, Laender JD, Oei TI, Bogaerts S. Field validity of the HCR-20 in forensic medium security units in Flanders. Psychol Crime Law. 2017:23:305-22.

9. Jeandarme I, Edens JF, Habets P, Bruckers L, Oei K, Bogaerts S. PCL-R field validity in prison and hospital settings. Law Hum Behav. 2017:41:29-43.

10. Viljoen JL, McLachlan K, Vincent GM. Assessing violence risk and psychopathy in juvenile and adult offenders: a survey of clinical practices. Assessment. 2010:17:377-95.

11. Fazel S. The scientific validity of current approaches to violence and criminal risk assessment. In: de Keijser JW, Roberts JV, Ryberg J, editors. Predictive sentencing: normative and empirical perspectives. London: Hart; 2019. p. 197-212.

12. Fazel S, Fimińska Z, Cocks C, Coid J. Patient outcomes following discharge from secure psychiatric hospitals: systematic review and meta-analysis. $\mathrm{Br}$ J Psychiatry. 2016;208:17-25.

13. Probst T, Bezzel A, Hochstadt M, Pieh C, Mache W. Criminal recidivism after forensic psychiatric treatment. A multicenter study on the role of pretreatment, treatment-related, and follow-up variables. J Forensic Sci. 2020;65:1221-4.

14. Davies S, Clarke M, Hollin C, Duggan C. Long-term outcomes after discharge from medium secure care: a cause for concern. $\mathrm{Br}$ J Psychiatry. 2007;191:70-4

15. Wolf A, Fanshawe TR, Sariaslan A, Cornish R, Larsson H, Fazel S. Prediction of violent crime on discharge from secure psychiatric hospitals: a clinical prediction rule (FoVOx). Eur Psychiatry. 2018;47:88-93.

16. Krebs J, Negatsch V, Berg I, Aigner A, Opitz-Welke A, Seidel P, et al. Applicability of two violence risk assessment tools in a psychiatric prison hospital population. Behav Sci Law. 2020;38:1-11.

17. Vasileiou K, Barnett J, Thorpe S, Young T. Characterising and justifying sample size sufficiency in interview-based studies: systematic analysis of qualitative health research over a 15-year period. BMC Med Res Methodol. 2018:18:148

18. Faulkner $L$. Beyond the five-user assumption: benefits of increased sample sizes in usability testing. Behav Res Methods Instrum Comput. 2003;35:379-83 
19. Cornish R, Lewis A, Curwell-Parry O, Ciobanasu O, Mallett S, Fazel S. A clinical feasibility study of the forensic psychiatry and violence Oxford (FoVOx) Tool. Front Psychiatry. 2019;10:901.

20. Cohen J. A coefficient of agreement for nominal scales. Educ Psychol Meas. 1960;20:37-46

21. Ran M-S, Chen P-Y, Liao Z-G, Chan CL-W, Chen EY-H, Tang C-P, et al, Criminal behavior among persons with schizophrenia in rural China. Schizophr Res. 2010;122:213-8.

22. Grann M, Danesh J, Fazel S. The association between psychiatric diagnosis and violent re-offending in adult offenders in the community. BMC Psychiatry. 2008;8:92

23. Gulati G, Cornish R, Al-Taiar H, Miller C, Khosla V, Hinds C, et al. Web-based violence risk monitoring tool in psychoses: pilot study in community forensic patients. J Forensic Psychol Pract. 2016;16:49-59.

24. Singh JP, Desmarais SL, Hurducas C, Arbach-Lucioni K, Condemarin C, Dean $\mathrm{K}$, et al. International perspectives on the practical application of violence risk assessment: a global survey of 44 countries. Int J Forensic Ment Health. 2014;13:193-206

25. Wang L, Ross CA, Zhang T, Dai Y, Zhang $H$, Tao M, et al. Frequency of borderline personality disorder among psychiatric outpatients in Shanghai. J Personal Disord. 2012;26:393-401.

\section{Publisher's Note}

Springer Nature remains neutral with regard to jurisdictional claims in published maps and institutional affiliations.

Ready to submit your research? Choose BMC and benefit from:

- fast, convenient online submission

- thorough peer review by experienced researchers in your field

- rapid publication on acceptance

- support for research data, including large and complex data types

- gold Open Access which fosters wider collaboration and increased citations

- maximum visibility for your research: over $100 \mathrm{M}$ website views per year

At $\mathrm{BMC}$, research is always in progress.

Learn more biomedcentral.com/submissions 